\title{
Application of $C$. elegans cancer screening test for the detection of pancreatic tumor in genetically engineered mice
}

\author{
Yuji Ueda1,2,3, Koichi Kawamoto1,2,3, Masamitsu Konno ${ }^{2,3}$, Kozo Noguchi, ${ }^{1,2}$, Satoru \\ Kaifuchi ${ }^{4}$, Taroh Satoh ${ }^{3}$, Hidetoshi Eguchi ${ }^{1}$, Yuichiro Doki ${ }^{1}$, Takaaki Hirotsu ${ }^{4,5}$, \\ Masaki Mori ${ }^{1}$ and Hideshi Ishii ${ }^{2,3}$ \\ ${ }^{1}$ Department of Gastroenterological Surgery, Graduate School of Medicine, Osaka University, Osaka 565-0871, Japan \\ ${ }^{2}$ Department of Medical Data Science, Graduate School of Medicine, Osaka University, Osaka 565-0871, Japan \\ ${ }^{3}$ Department of Frontier Science for Cancer and Chemotherapy, Graduate School of Medicine, Osaka University, Osaka \\ 565-0871, Japan \\ ${ }^{4}$ Hirotsu Bioscience Co., Ltd., Tokyo 107-0062, Japan \\ ${ }^{5}$ Department of Biology, Graduate School of Science, Kyushu University, Fukuoka 819-0395, Japan \\ Correspondence to: Hideshi Ishii, email: hishii@gesurg.med.osaka-u.ac.jp \\ Keywords: early detection; pancreatic cancer; C. elegans; genetically-engineered mice \\ Abbreviations: PDAC: pancreatic ductal adenocarcinoma; C.elegans: Caenorhabditis elegans \\ Received: July 02, $2019 \quad$ Accepted: July 17, $2019 \quad$ Published: September 10, 2019 \\ Copyright: Ueda et al. This is an open-access article distributed under the terms of the Creative Commons Attribution License 3.0 \\ (CC BY 3.0), which permits unrestricted use, distribution, and reproduction in any medium, provided the original author and source \\ are credited.
}

\section{ABSTRACT}

Pancreatic ductal adenocarcinoma (PDAC) exhibits a very early onset of metastasis. Thus, early detection and treatment are pivotal to successful eradication of pancreatic cancers. Economical and non-invasive cancer screening systems is indispensable for this purpose. Previously our group developed a novel method to detect various kinds of human cancer using nematode Caenorhabditis elegans (C. elegans) that respond to cancer odor in urine; however, whether this method is useful for non-human species remains to be understood. In this study, we examined its effectiveness in the detection of murine pancreatic tumor spontaneously generated in genetically-engineered mice. We generated pancreas-specific Kras ${ }^{\mathrm{G12D}}$ and/or c-Met deletion mutant mice and measured the probability of spontaneous tumor generation in these mice. The chemotactic indexes of $C$. elegans to the urine samples of these mutant mice were measured. As previously described, oncogenic Kras ${ }^{G 12 D}$ was necessary to induce pancreatic intraepithelial neoplasia in this mouse model, while c-Met mutation did not show further effect. The chemotactic analysis indicated that C. elegans avoids urine of healthy recipient mice, while they tended to be attracted to urine of mice with $\operatorname{Kras}^{G 12 D}$. Our study demonstrated that $C$. elegans can recognize the odor of pancreatic cancer in urine of $\operatorname{Kras}^{G 12 D}$ model mouse, suggesting the similarity of cancer odor between species. Our result facilitates further studies on mechanism of cancer detection by $C$. elegans.

\section{INTRODUCTION}

Pancreatic ductal adenocarcinoma (PDAC) is one of the most lethal cancers, and the fourth most common cause of cancer death across the world [1-2]. Complete surgical resection is the only way for long-term survival of the patients of PDAC. However, 5-year-survival rate of curative pancreatic cancer has not improved substantially in the past 30 years [1-3]. One reason why pancreatic cancer has a dismal prognosis may be asymptomatic nature of the disease. Many of PDAC patients have metastases at the time of diagnosis [2]. Thus, early-stage diagnosis of PDAC is definitely important to improve its prognosis.

Currently, carcinoembryonic antigen (CEA) and carbohydrate antigen 19-9 (CA19-9) are ones of the 
most established biomarkers used for the detection and management of pancreatic cancer [4]. However, sensitivity and specificity of these markers are not good enough for effectively screening pancreatic cancer in clinical practice. Thus, identification of novel biomarker for the detection of early stage of pancreatic cancer is indispensable to improve the survival of pancreatic cancer patients.

Recent progress in the study of geneticallyengineered mouse model (GEMM) revealed the process of pancreatic tumorigenesis and enabled us to detect minimal change in early stage of PDAC [5]. It was reported that epithelial-to-mesenchymal transition (EMT) and dissemination precede pancreatic tumor formation in spontaneous tumor mice model $[6,7]$. Nearly all PDAC and a high percentage of early pancreatic intraepithelial neoplasia (PanIN) lesions have KRAS mutations. It was reported that seeding and propagation of untransformed mouse mammary cells having Kras mutation in the lung [8]. The human acinar-to-ductal metaplasia (ADM)-toPanIN-to-PDAC progression has been recapitulated using GEMMs [9, 10].

C. elegans has a highly developed chemosensory system and can detect a wide variety of volatile and water-soluble chemicals associated with food, danger, or other animals. Because of its short lifespan and hermaphroditic nature, C. elegans is easy to be maintained in laboratories and therefore widely used as genetic model in research. Previously, we found that $C$. elegans can detect the odor of cancer in urine of cancer patients $[11,12]$. Based on this finding, we developed a novel and highly accurate cancer detection system, Nematode Scent Detection Test (NSDT) that is also economical, painless, rapid and convenient. In our report among 20 cancer patients tested, six cases were early stage cancer (stage 0 or 1), suggesting that NSDT can be used for screening of early cancer. However, our data contained only one patient with pancreatic cancer, which was at advanced stage. Thus, the effectiveness of $C$. elegans to detect early stage of pancreatic cancer has not been fully analyzed.

In mice, various kinds of strains that develop pancreatic tumor have been reported. Therefore, we decided to assess the possibility of NSDT to detect pancreatic tumor using mouse model. Oncogene Kras plays a role in the generation of pancreatic cancer, and its activation is observed in $>95 \%$ cases of PDAC patients [2]. Kras ${ }^{\mathrm{G} 12 \mathrm{D}}$ point mutation allele is commonly associate with human cancer and leads to a constitutive active form of Kras. On the other hand, c-Met is involved in the chemotherapy resistant phonotype of pancreatic cancer $[13,14]$. Therefore, we have generated mutation of Kras in pancreas specific manner in mice, which was compared with pancreas specific deletion of c-Met, as described [14].

\section{RESULTS}

\section{Tumor formation in genetically-engineered model mice}

We used a Cre-loxP-based mouse model of PDAC to assess the possibility of $C$. elegans to detect the putative odours from tumor-bearing mice. First, we assessed the tumorigenicity of oncogenic $\operatorname{KRas}^{G 12 D}$ mice in which $\operatorname{Kras}^{G 12 D}$ oncogene was specifically introduced in pancreas. As shown in Figure 1, 3 out of 12 (25\%) $\operatorname{Kras}^{G 12 D}$ mice have developed pancreatic tumor. Then we crossed $\operatorname{Kras}^{G 12 D}$ mice with $c$-Met mutant mice to obtain $\mathrm{KRas}^{G 12 D} / \mathrm{c}$-Met double mutant mice, and assessed the tumorigenicity. 8 out of $13(61.5 \%) \mathrm{KRas}^{G 12 D} / \mathrm{C}$-Met mice have developed pancreatic tumor (Figure 1). The occurrence of tumors was not affected by $c$-Met deletion. These results demonstrated that spontaneous tumor was observed only in $\mathrm{Kras}^{G 12 D}$-bearing mice, suggesting that $\operatorname{Kras}^{G 12 D}$ mutation is necessary for the development of pancreatic tumor [13-15] (Table 1). We then used urines from these mice for the assessment of cancer detection by C. elegans.

\section{Detection of tumor in mice by $C$. elegans scent}

To test the possibility that $C$. elegans can detect odors of tumor generated in these mouse models, we performed the chemotaxis assay (Figure 2A). Our previous study

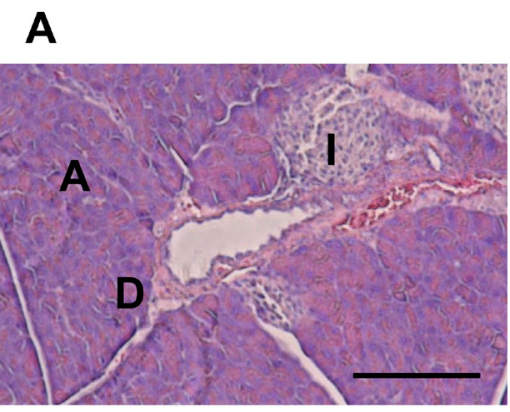

Normal Pancreas

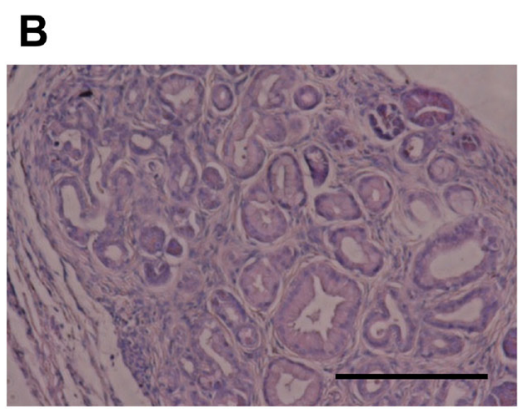

PanIN 2

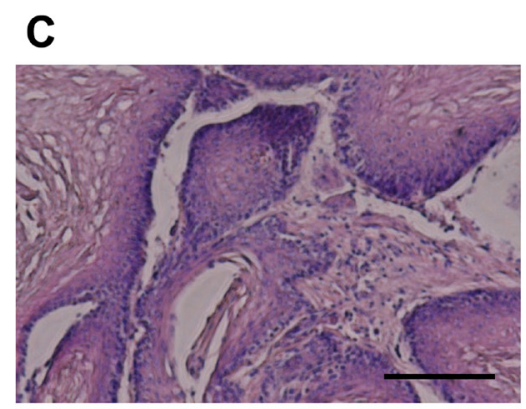

Adenocarcinoma

Figure 1: HE staining for pancreatic tissue. (A) Normal pancreatic tissue in LSL-KRAS ${ }^{\mathrm{G} 12 \mathrm{D}}$ negative and c-Met Wt mouse. Scale bar, $100 \mu \mathrm{m}$; PanIN, pancreatic intraepithelial neoplasia; A, acinar cell; I, islet. (B) PanIN 2 Pancreatic Tissue in LSL-KRAS ${ }^{\mathrm{G} 12 \mathrm{D}}$ positive and c-Met Wt mouse. (C) Adenocarcinoma Pancreatic Tissue in LSL-KRAS ${ }^{\mathrm{G} 12 \mathrm{D}}$ positive and c-Met WT mouse. 
Table 1: Genotype for mouse harvested urine

\begin{tabular}{|c|c|c|c|c|c|}
\hline Type & Pdx1-Cre & $L S L-K R A S^{\mathrm{G} 12 \mathrm{D}}$ & c-Met & Gender & Days \\
\hline 1a & $\mathrm{Tg}$ & Negative & $\mathrm{Wt}$ & $\mathrm{F}$ & 249 \\
\hline $1 b$ & $\mathrm{Tg}$ & Negative & Wt & $\mathrm{F}$ & 364 \\
\hline 1 & $\mathrm{Tg}$ & Negative & Wt & $\mathrm{F}$ & 273 \\
\hline 2 & $\mathrm{Tg}$ & Positive & Wt & $\mathrm{F}$ & 244 \\
\hline 2 & $\mathrm{Tg}$ & Positive & $\mathrm{Wt}$ & M & 273 \\
\hline 2 & $\mathrm{Tg}$ & Positive & Wt & M & 383 \\
\hline 3 & $\mathrm{Tg}$ & Negative & flox/flox & M & 290 \\
\hline 3 & $\mathrm{Tg}$ & Negative & flox/flox & M & 308 \\
\hline 3 & $\mathrm{Tg}$ & Negative & flox/flox & M & 307 \\
\hline 3 & $\mathrm{Tg}$ & Negative & flox/flox & M & 326 \\
\hline 3 & $\mathrm{Tg}$ & Negative & flox/flox & $\mathrm{M}$ & 326 \\
\hline 3 & $\mathrm{Tg}$ & Negative & flox/flox & M & 311 \\
\hline 3 & $\mathrm{Tg}$ & Negative & flox/flox & M & 318 \\
\hline 3 & $\mathrm{Tg}$ & Negative & flox/flox & $\mathrm{F}$ & 318 \\
\hline 3 & $\mathrm{Tg}$ & Negative & flox/flox & $\mathrm{F}$ & 314 \\
\hline 4 & $\mathrm{Tg}$ & Positive & flox/flox & M & 286 \\
\hline 4 & $\mathrm{Tg}$ & Positive & flox/flox & M & 290 \\
\hline 4 & $\mathrm{Tg}$ & Positive & flox/flox & $\mathrm{F}$ & 332 \\
\hline 4 & $\mathrm{Tg}$ & Positive & flox/flox & $\mathrm{F}$ & 318 \\
\hline
\end{tabular}

(Tg: transgenic mouse, F: female, M: male).

demonstrated that chemotactic response of $C$. elegans to serum was not significantly different between healthy volunteers and cancer patients at any concentrations. This may be due to the presence of other odorants or molecules in the serum that mask the smell of tumor-derived molecules. Therefore, in the current mouse study, we used urine to confirm the result of human study. As the urinary concentration of mice is higher than that of human, samples were diluted at $10^{-2}$ and $10^{-3}$ before analysis [16]. Although the magnitudes of chemotactic responses were less than human cases, $C$. elegans showed avoidance against urine from healthy control littermates (Figure 2B, 2C). c-Met deletion exhibited only minimal effects on these chemotactic responses (Figure 2B, 2C). C. elegans showed very weak attraction to only 2 out of 9 urine samples collected from c-Met mutant mice at $10^{-3}$ concentration. In contrast, the chemotactic index of C. elegans to urine from $\mathrm{Kras}^{G 12 D}$ mutation mice was significantly higher compared to urine of $\mathrm{Kras}^{G 12 D}$-negative control mice (Figure 2B, 2C). Five out of 7 urine samples from $\mathrm{Kras}^{\mathrm{G} 12 \mathrm{D}}$-positive mice attracted C. elegans at either $10^{-3}$ or $10^{-4}$ concentration, indicating that the sensitivity of this analysis to detect tumor is $71.4 \%$. On the contrary, 2 out of $12 \mathrm{Kras}^{\mathrm{G} 12 \mathrm{D}}$-negative mice attracted C. elegans, showing that the specificity of this analysis is $83.3 \%$. These results suggest that volatile odor would be present only in mice with $\mathrm{Kras}^{\mathrm{G} 12 \mathrm{D}}$ and suggest the possibility that the molecule would be downstream of $\operatorname{Kras}^{G 12 D}$ gene. Given that Kras gene controls the metabolic flux of glutamine in pancreatic cancer cells, we are interested in whether any detectable metabolites might influence on the behaviors of C. elegans [12].

\section{DISCUSSION}

Identification of volatile biomarkers for disease diagnosis, including various kinds of cancers, is an area of great interest and promise. Originally, it was reported that trained dogs can discriminate odor of cancer patients from healthy control. Several studies demonstrated that dogs can detect odor of various cancers including colon, melanoma, bladder, lung, breast and ovarian cancer in patients' urine or breath. However, considering the time and the cost required for dog education, it may be difficult to introduce canine scent detection into clinical practices. We have previously reported that C. elegans can effectively detect the odor of cancer in human urine [12]. In the present study, we demonstrated that $C$. elegans can also distinguish the odor of genetically-engineered mice from control siblings. The magnitude of chemotactic responses of $C$. elegans for murine urine $(-0.25$ to 0.2 ) was lower compared to that for human samples ( -0.3 to 0.4$)$. In addition, sensitivity $(71.4 \%)$ as well as specificity $(83.3 \%)$ of the analysis are not as high as for human samples ( $95.8 \%$ and $95.0 \%$, respectively). 
A

C. elegans cultures $\quad 1 \mathrm{M}$ sodium azide $0.5 \mu \mathrm{L}$
(on NGM)

(on NGM) + sample solution $1.0 \mu \mathrm{L}$
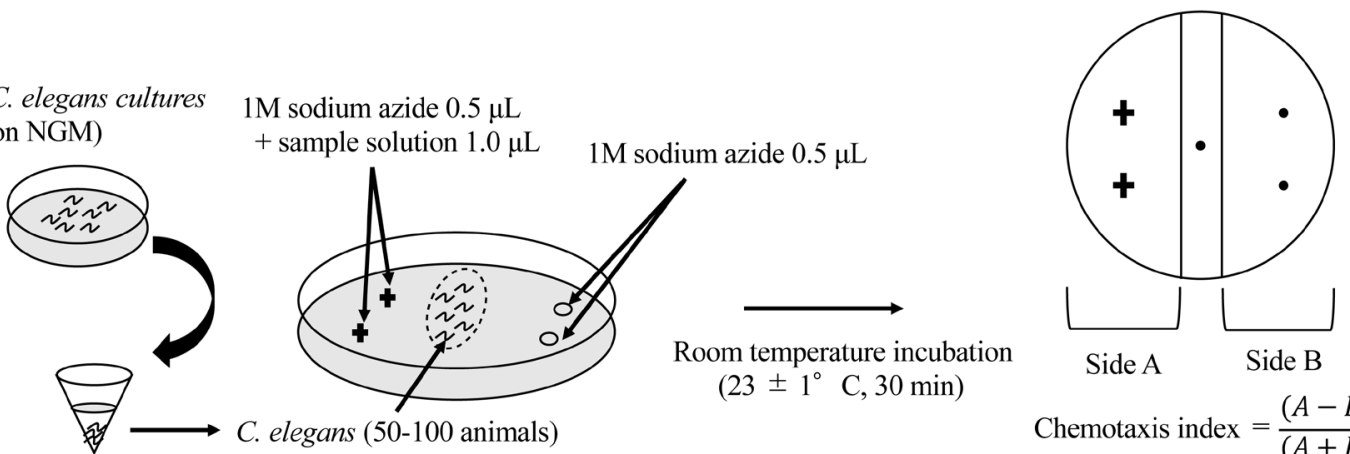

Chemotaxis index $=\frac{(A-B)}{(A+B)}$

B

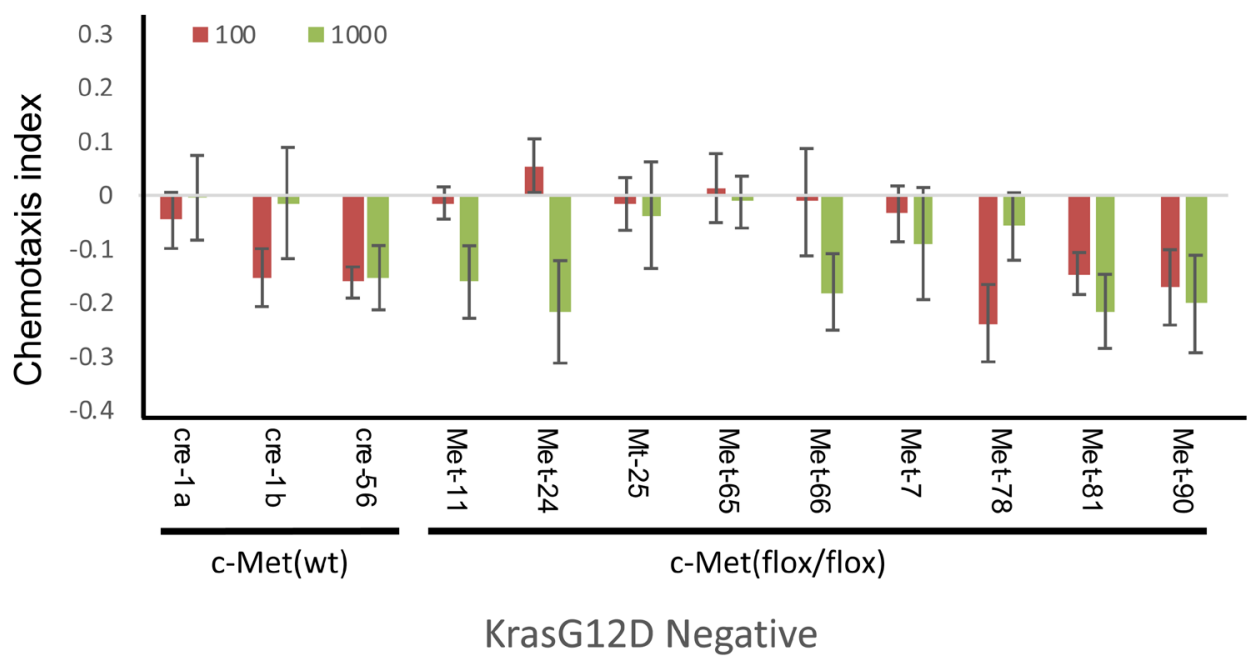

C

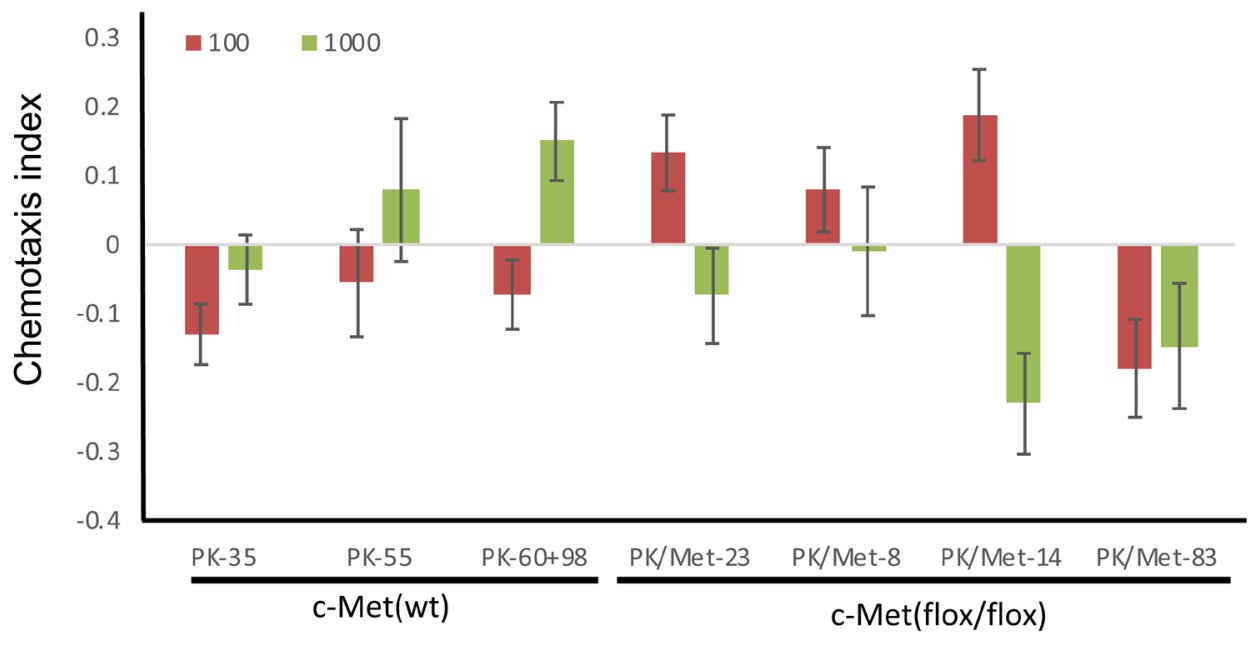

KrasG12D Positive

Figure 2: Detection of tumor in mice by C. elegans scent. (A) The method for chemotaxis assay using C. elegans. (B, C) The results for chemotaxis assay using $C$. elegans. Red bars mean samples were diluted at $10^{2}$ before analysis. Green bars mean samples were diluted at $10^{3}$ before analysis. Standard deviation was calculated using excel. 
The reason of this difference may be the specie specificity of cancer odorants. The further study will be necessary to confirm this hypothesis.

The lines of our studies showed that C. elegans has a potential to detect volatile components in urine from cancer bearing conditions, although the molecular characteristics of the components have not been identified. Moreover, we demonstrated in this study that C. elegans has potential to detect cancer odors across species, both for human and murine. Limitation of current study might that we did not directly compared human and murine samples.

Our next project is to reveal the effectiveness of this system on clinical samples of various kinds of progression of PDAC patients.

The progression of PanIN to PDAC also meant that this mouse model offers the opportunity to identify precancerous lesion. Pancreatic development is initially associated with the activation of pancreatic and duodenal homeobox 1 (Pdx1). Previously, in mice bearing Pdx1-Cre; Kras ${ }^{G 12 D}$; p53 $3^{\mathrm{fl} /+}$; $\operatorname{Rosa}^{\mathrm{YFP}}$ (PKCY) mutation, which develop pancreatic ductal adenocarcinoma, it was reported that pancreatic EMT and dissemination precedes pancreatic tumor formation [10]. It would be possible to diagnose PanIN stage by $C$. elegans because in PKCY mice circulating tumor cells (CTC) were detected in 8 to 10 -week old mice in PanIN stage. In this study, we did not assess the detection of CTC, Unresolved questions include whether diagnose using blood samples NSDT is highly economical diagnostic tool compared to traditional glycoprotein markers, such as CEA [17] and CA19-9 [17]. To detect cancer smells more precisely and quantitatively, it is necessary to identify specific cancer odours and their receptors. The reason why urine is suitable for decent detection has not been yet demonstrated.

\section{MATERIALS AND METHODS}

\section{Mouse models of pancreatic cancer}

Mice were maintained under specific-pathogen-free conditions and given free access to water and chow, under the ethical agreement of animal study in Osaka University (approved by professor Y. Kaneda as the approval number 24-122-022), of which experimental procedure had been performed as descried previously [14]. Briefly, Kras ${ }^{\mathrm{LSL}-}$ G12D strain carries a loxP-stop-loxP sequence followed by constitutive active form of $\mathrm{Kras}^{\mathrm{G} 12 \mathrm{D}}$. $\mathrm{Kras}^{\mathrm{LSL}-\mathrm{G} 12 \mathrm{D}}$ mice were obtained from the National Cancer Institute National Institutes of Health, Bethesda, MD, USA. Met tlox/flox $^{\text {, }}$ transgenic mice from a BL6 background were obtained from the National Cancer Institute (National Institutes of Health, Bethesda, MD, USA) [15]. Pdx-1 promoter driven $\mathrm{Cre}^{+/-}$mice, which express Cre specifically in pancreas were obtained from the National Cancer Institute National Institutes of Health, Bethesda, MD, USA. We have introduced $\mathrm{Kras}^{\mathrm{G} 12 \mathrm{D}}$ mutation in pancreas specific manner, by crossing $\mathrm{Kras}^{\mathrm{LSL}-\mathrm{G} 12 \mathrm{D} /+}$ mice with $\mathrm{Pdx}-1-\mathrm{Cre}^{+/-}$ mice. Kras ${ }^{L S L-G 12 D}$ mice were crossbred to $c-M e t^{F x}$ to obtain mixed background (C57Bl/6/129/Sv) Kras ${ }^{L S L-G 12 D /+} ; c-$ $\mathrm{Met}^{\mathrm{Fx} / \mathrm{Fx}}$ (for spontaneous tumors) or $\mathrm{Kras}^{+/+}, \mathrm{c}-\mathrm{Met}^{+/+}$ (control recipients) mice [14, 15]. We have generated mutation of Kras in pancreas specific manner in mice, which was compared with pancreas specific deletion of c-Met, as described [15]. In brief, pancreas specific transcription factor Pdx-1 driven $\mathrm{Cre}^{/+}$mice, $\mathrm{Kras}^{\mathrm{LSL}-\mathrm{G} 12 \mathrm{D} /+}$ mice and $\mathrm{Met}^{\text {flox/flox }}$ transgenic mating pairs of $\sim 6$ weeks old male and female mice from a BL6 background were obtained from the National Cancer Institute (National Institutes of Health, Bethesda, MD, USA) [15]. The Pdx$1 \mathrm{Cre}^{/+}$mice were crossed with $\mathrm{Kras}^{\text {Lox-Stop-Lox(LSL)-G12D/+ }}$ mice or $\mathrm{Met}^{\text {flox/flox }}$ mice to generate $\mathrm{Pdx}-1 \mathrm{Cre}^{/+} / \mathrm{Kras}^{\mathrm{LSL}-\mathrm{G} 12 \mathrm{D} /+}$ and $\mathrm{Pdx}-1 \mathrm{Cre}^{+/} / \mathrm{Met}^{\text {flox/flox }}$ mice; both were crossed to generate double knockout, $\mathrm{Pdx}-1 \mathrm{Cre}^{/+} / \mathrm{Kras}^{\mathrm{LSL}-\mathrm{G} 12 \mathrm{D} /+} / \mathrm{Met}^{\text {flox/flox }}$ mice. The genotypes were confirmed that alleles of Pdx$1 \mathrm{Cre}^{/+}, \mathrm{KRAS}^{\mathrm{LSL}-\mathrm{G} 12 \mathrm{D} /+}$ and $\mathrm{Met}^{\text {flox/flox }}$ were present in the pancreases, but not tails, of compound mutant mice [15]. All experiments used co-housed littermates to ensure the consistency of microflora; the temperature was $\sim 22^{\circ} \mathrm{C}$ in $12 \mathrm{~h}$-cycle of light and dark, and food and water were added in adlibitum [15]. Samples such as urines was stored in freezer at $-20^{\circ} \mathrm{C}$ until use.

\section{C. elegans cultures and strains}

C. elegans strains were cultured at $20^{\circ} \mathrm{C}$ under standard conditions on Nematode Growth Medium (NGM) plates (1.7\% Bacto agar, 0.5\% Bacto peptone, $50 \mathrm{mM} \mathrm{NaCl}, 25 \mathrm{mM}$ potassium phosphate buffer $\mathrm{pH}$ 6.0, $1 \mathrm{mM} \mathrm{CaCl}_{2}, 1 \mathrm{mM} \mathrm{MgSO}$ and $5 \mu \mathrm{g} / \mathrm{mL}$ cholesterol) with Escherichia coli NA22, which grows in thick layers that serve as a suitable food source for large scale worm cultures used for chemotaxis analyses. The strain used in this study was wild type N2.

\section{Chemotaxis assays}

The chemotaxis assays were performed using approximately synchronized young adult $C$. elegans. Grown nematode on NGM were collected in microfuge tubes and washed three times with basal buffer $(5 \mathrm{mM}$ potassium phosphate buffer $\mathrm{pH} 6.0,1 \mathrm{mM} \mathrm{CaCl}_{2}, 1 \mathrm{mM}$ $\mathrm{MgSO}_{4}$ and $0.5 \mathrm{~g} / \mathrm{L}$ gelatin). The nematode that settled at the bottom were taken and about 50-100 animals were spotted at the center of $9 \mathrm{~cm}$ assay plates $(2.0 \%$ Bacto agar, $5 \mathrm{mM}$ potassium phosphate buffer $\mathrm{pH} 6.0,1 \mathrm{mM}$ $\left.\mathrm{CaCl}_{2}, 1 \mathrm{mM} \mathrm{MgSO}_{4}\right) .1 \mu \mathrm{L}$ each of sample solution and 1 $\mathrm{M}$ sodium azide were spotted on two points separated by about $2.5 \mathrm{~cm}$ at one end of the plates. Only sodium azide was similarly spotted on the other side. The assays were conducted at the room temperature of $23 \pm 1^{\circ} \mathrm{C}$ at 30 min. The chemotaxis index was calculated [12] (Figure 2) by using the formula, the chemotaxis index $=(\mathrm{A}-\mathrm{B}) /(\mathrm{A}$ $+B)$. Here, the side $A$ was the number of animals on the sample-spotted side of the plate and B was the number 
of the animals on the opposite side, while animals that remained within $0.5 \mathrm{~cm}$ of the midline ignored to exclude immotile animals from consideration. Only well-fed nematodes were used in this study because starvation may affect their chemotactic responses.

\section{Sample collection}

Urine samples were obtained by utilizing small pipet and $1.5 \mathrm{ml}$ Eppendorf tubes as containers and on daytime. Approximately $1 \mathrm{ml}$ urine was collected from each mouse, added to a polypropylene screw cap tube and stored at $-20^{\circ} \mathrm{C}$ until use.

\section{Histopathological analysis}

Pancreas from each mouse strain were removed and fixed with formalin. Paraffin-emended tissue sections were prepared as previously demonstrated [13, 14]. The specimens were then stained with hematoxylin and eosin. All sections were viewed with a Keyence BZ-9000 (Keyence Corp.).

\section{Statistical analysis}

Differences in participants' characteristics, laboratory data and tumour markers between the control and cancer participants were examined using the paired t-test for continuous variables and the $\chi 2$ test for dichotomized variables. A $P$-value of $<0.05$ was considered statistically significant.

\section{CONFLICTS OF INTEREST}

Institutional endowments were received from Taiho Pharmaceutical Co., Ltd (Tokyo, Japan) [to Dr. H. Ishii], Evidence Based Medical Research Center INC. (Osaka, Japan) [to Dr. H. Ishii], UNITECH Co., Ltd. (Chiba, Japan) [to Dr. H. Ishii], IDEA Consultants, Inc. (Tokyo, Japan) [to Dr. H. Ishii], Kinshu-kai Medical Corporation (Osaka, Japan) [to Dr. H. Ishii], Chugai Co., Ltd. (London, UK) [to Dr. T. Satoh], Yakult Honsha Co., Ltd. [to Dr. T. Satoh], Ono Pharmaceutical Co., Ltd. (Osaka, Japan) [to Dr. T. Satoh], and Merck \& Co., Ltd. (Whitehouse Station, NJ, USA) [to Dr. T. Satoh]; those sponsors had no role in the design or performance of the study, data collection, data management and interpretation, preparation of this article, or approval of the article. Drs. S. Kaifuchi and T. Hirotsu is employees of Hirotsu Bioscience Co., Ltd. (Tokyo, Japan).

\section{FUNDING}

This work received financial support from grants-inaid for Scientific Research from the Ministry of Education, Culture, Sports, Science, and Technology (grant nos. 16K15591; 15H05791).

\section{REFERENCES}

1. Colvin H, Mizushima T, Eguchi H, Takiguchi S, Doki Y, Mori M. Gastroenterological surgery in Japan: the past, the present and the future. Ann Gastroenterol Surg. 2017; 1:5-10. https://doi.org/10.1002/ags3.12008. [PubMed]

2. Garrido-Laguna I, Hidalgo M. Pancreatic cancer: from state-of-the-art treatments to promising novel therapies. Nat Rev Clin Oncol. 2015; 12:319-34. https://doi.org/10.1038/ nrclinonc.2015.53. [PubMed]

3. Von Hoff DD, Ervin T, Arena FP, Chiorean EG, Infante J, Moore M, Seay T, Tjulandin SA, Ma WW, Saleh MN, Harris M, Reni M, Dowden S, et al. Increased survival in pancreatic cancer with nab-paclitaxel plus gemcitabine. N Engl J Med. 2013; 369:1691-703. https://doi.org/10.1056/ NEJMoa1304369. [ubMed]

4. Tomihara H, Eguchi H, Yamada D, Gotoh K, Kawamoto K, Wada H, Asaoka T, Noda T, Takeda Y, Tanemura M, Mori M, Doki Y. Preoperative chemoradiotherapy does not compromise the feasibility of adjuvant chemotherapy for patients with pancreatic ductal adenocarcinoma. Surg Today. 2017; 47:218-26. https://doi.org/10.1007/s00595016-1405-6. [PubMed]

5. Silva ML. Cancer serum biomarkers based on aberrant posttranslational modifications of glycoproteins: clinical value and discovery strategies. Biochim Biophys Acta. 2015; 1856:165-77. https://doi.org/10.1016/j.bbcan.2015.07.002. [PubMed]

6. Colvin EK, Scarlett CJ. A historical perspective of pancreatic cancer mouse models. Semin Cell Dev Biol. 2014; 27:96105. https://doi.org/10.1016/j.semcdb.2014.03.025. [PubMed]

7. Rhim AD, Mirek ET, Aiello NM, Maitra A, Bailey JM, McAllister F, Reichert M, Beatty GL, Rustgi AK, Vonderheide RH, Leach SD, Stanger BZ. EMT and dissemination precede pancreatic tumor formation. Cell. 2012; 148:349-61. https:// doi.org/10.1016/i.cell.2011.11.025. [PubMed]

8. Podsypanina K, Du YC, Jechlinger M, Beverly LJ, Hambardzumyan D, Varmus H. Seeding and propagation of untransformed mouse mammary cells in the lung. Science. 2008; 321:1841-44. https://doi.org/10.1126/ science.1161621. [PubMed]

9. Uesaka K, Boku N, Fukutomi A, Okamura Y, Konishi M, Matsumoto I, Kaneoka Y, Shimizu Y, Nakamori S, Sakamoto H, Morinaga S, Kainuma O, Imai K, et al, and JASPAC 01 Study Group. Adjuvant chemotherapy of S-1 versus gemcitabine for resected pancreatic cancer: a phase 3, open-label, randomised, non-inferiority trial (JASPAC 01). Lancet. 2016; 388:248-57. https://doi.org/10.1016/ S0140-6736(16)30583-9. [PubMed]

10. Yamada D, Eguchi H, Asaoka T, Tomihara H, Noda T, Wada H, Kawamoto K, Gotoh K, Takeda Y, Tanemura M, Mori $\mathrm{M}$, Doki Y. The basal nutritional state of PDAC patients is the dominant factor for completing adjuvant chemotherapy. Surg Today. 2017; 47:1361-71. https://doi.org/10.1007/ s00595-017-1522-x. [PubMed] 
11. Hirotsu T, Saeki S, Yamamoto M, Iino Y. The Ras-MAPK pathway is important for olfaction in Caenorhabditis elegans. Nature. 2000; 404:289-93. https://doi.org/10.1038/35005101. [PubMed]

12. Hirotsu T, Sonoda H, Uozumi T, Shinden Y, Mimori K, Maehara Y, Ueda N, Hamakawa M. A highly accurate inclusive cancer screening test using Caenorhabditis elegans scent detection. PLoS One. 2015; 10:e0118699. https://doi. org/10.1371/journal.pone.0118699. [PubMed]

13. Noguchi K, Eguchi H, Konno M, Kawamoto K, Nishida N, Koseki J, Wada H, Marubashi S, Nagano H, Doki Y, Mori M, Ishii H. Susceptibility of pancreatic cancer stem cells to reprogramming. Cancer Sci. 2015; 106:1182-87. https://doi. org/10.1111/cas.12734. [PubMed]

14. Noguchi K, Konno M, Eguchi H, Kawamoto K, Mukai R, Nishida N, Koseki J, Wada H, Akita H, Satoh T, Marubashi $\mathrm{S}$, Nagano H, Doki Y, et al. c-Met affects gemcitabine resistance during carcinogenesis in a mouse model of pancreatic cancer. Oncol Lett. 2018; 16:1892-98. https:// doi.org/10.3892/ol.2018.8793. [PubMed]

15. Son J, Lyssiotis CA, Ying H, Wang X, Hua S, Ligorio M, Perera RM, Ferrone CR, Mullarky E, Shyh-Chang N, Kang Y, Fleming JB, Bardeesy N, et al. Glutamine supports pancreatic cancer growth through a KRAS-regulated metabolic pathway. Nature. 2013; 496:101-05. https://doi. org/10.1038/nature12040. [PubMed]

16. Yang B, Bankir L. Urea and urine concentrating ability: new insights from studies in mice. Am J Physiol Renal Physiol. 2005; 288:F881-96. https://doi.org/10.1152/ ajprenal.00367.2004. [PubMed]

17. Hanash SM, Baik CS, Kallioniemi O. Emerging molecular biomarkers - blood-based strategies to detect and monitor cancer. Nat Rev Clin Oncol. 2011; 8:142-50. https://doi. org/10.1038/nrclinonc.2010.220. [PubMed] 